\title{
SUBCUTANEOUS PHYCOMYCOSIS: A CASE REPORT
}

\author{
Garima Sharma1, Anil Kumar Gupta²
}

\section{HOW TO CITE THIS ARTICLE:}

Garima Sharma, Anil Kumar Gupta. "Subcutaneous Phycomycosis: A case report". Journal of Evolution of Medical and Dental Sciences 2014; Vol. 3, Issue 72, December 22; Page: 15324-15326,

DOI: $10.14260 /$ jemds/2014/4063

\begin{abstract}
Subcutaneous phycomycosis is a rare fungal infection of the subcutaneous tissue caused by Zygomatous group of fungi. We report an rare case of an 60 years old farmer with nasal subcutaneous phycomycosis which presented as painless, non-tender, swelling on his nose. Local examination revealed a non-tender, dull, erythematous, woody hard, uniform, smooth, non-pitting swelling on the root of the nose, extending to the upper lips, left and right cheek. The overlying skin was intact, and a finger could be insinuated beneath the swelling. Histopathological analysis of the biopsied tissues revealed chronic granulomatous inflammation containing fungal hyphae with surrounding langhans giant cells and eosinophilia. The swelling decreased in the second month of treatment after the patient was started on oral itraconazole.
\end{abstract}

KEYWORDS: Phycomycosis; zygomatous fungi; potassium iodide; Azole.

INTRODUCTION: Subcutaneous phycomycosis is a rare, chronic, localized, subcutaneous zygomycosis, characterized by painless, woody swelling of the rhinofacial region. The disease occurs mainly in the tropical rain forests of Africa, South-East Asia. A few cases have been reported from India. We report a case of this rare subcutaneous phycomycosis.

CASE REPORT: A 60 year old farmer presented to opd with a slowly progressive swelling of the nose, forehead, upper lip and nasal block of 2 year duration. He was treated earlier with various antibiotics, with no improvement.

General and systemic examinations were unremarkable, except for a disfigured facial appearance. Local examination revealed a non-tender, dull, erythematous, woody hard, uniform, smooth, non-pitting swelling on the root of the nose, extending to the upper lips, left and right cheek and forehead. The overlying skin was intact, and a finger could be insinuated beneath the swelling. There was no regional lymph node enlargement.

The patient did not have a history of fever, vomiting, and his history was not suggestive of any significant illness

Routine blood examination was normal. X-ray of paranasal sinuses showed features of frontal and maxillary sinusitis.

The biopsied tissue was sent for potassium hydroxide preparation and fungal culture. Broad thin walled non-septate mycelia were found in the $\mathrm{KOH}$ preparation.

The patient was treated with capsul itraconazole $200 \mathrm{mg}$ twice a day for 3 month with remarkable improvement. After 3 months itraconazole dose tapered to $100 \mathrm{mg}$ twice day. Patient is still on follow up.

DISCUSSION: Subcutaneous phycomycosis is a fungal infection of the subcutaneous fats caused by Zygomatous group of fungi in the family Entomophthoraceae, mainly in the genus Basidiobolus (common in children) and Conidiobolus in adults (Prasad PV, 2002). ${ }^{1}$ The causative organisms are 


\section{CASE REPORT}

Basidiobolus ranarum and Conidiobolus coronatus respectively. It can cause a variety of clinical manifestations including subcutaneous zygomycosis, gastrointestinal zygomycosis and occasionally an acute systemic illness.

Documentations as early as 1886 describe this fungus as a saprophyte in the gastro-intestinal tract of reptiles and amphibians. Soil and vegetation contaminated by faeces from these animals seems a likely source of the infection in man (JOE HF, 1980). ${ }^{2}$ Reports have shown fungal spores to be found on the bristles of mites other insects. When these are eaten by reptiles and amphibians, the saprophytic cycle of the fungus is complete. Such mites and insects may comprise a further possible source of infection in man (HC, 1999). ${ }^{2}$

Granulomatous lesions due to Basidiobolus ranarum have been found in the nostrils and on the legs of horses, but reports on animal infection are scanty. In humans a chronic infection of the subcutaneous tissue is usually produced characterized by the formation of firm and non-tender swellings, generally on the extremities, trunk and rarely other parts of the body. Our patient is among the rare cases as he presented with a nasal swelling. The disease appears to be a primary rather than a secondary infection, no predisposing factors are known (HC, 1999). ${ }^{3}$ The disease usually occurs in children, less often in adolescents and rarely in adults. Males are much more frequently affected than females.

Definitive diagnosis is made by histopathological analysis of the tissues from the swellings. Features are of extensive dermal and subcutaneous fibrosis and large zygomatic hyphae. The hyphae appear as short sections of broad hyphae without septae. Granulomatous inflammatory features may also be present (Manjir RN, 2009). ${ }^{4}$

Most patients with phycomycosis respond very well to oral potassium iodide therapy as also to azoles (Sujatha S, 2003). ${ }^{5}$ Our patient also responded well to itraconazole and the swelling reduced dramatically after one month of treatment.Relapse chances are high in patient who undergo excisional biopsy(Manjir RN, 2009). ${ }^{4}$ Hence surgery should be avoided as it may hasten the spread of infection.

Treatment of subcutaneous phycomycosis is difficult because the diagnosis is usually established late, but patients often respond to oral potassium iodide, oral itraconazole (200 to 400 $\mathrm{mg}$ /day), ketoconazole (200 to $400 \mathrm{mg} /$ day), fluconazole (100-200 mg/day), amphotericin-B, and cotrimoxazole. Of these, itraconazole andfluconazole are both effective and relatively safe. Treatment should be continued for at least 1 month after the lesions have cleared.

\section{REFERENCES:}

1. Burkitt DP, W. A., Jellife DB. (1964). Subcutaneous Phycomycosis: A review of 31 cases seen in Uganda. British Medical Journal, 1, 1669-1672.

2. HC, G. (1999). A review of Zygomycosis due to Basidiobolus ranarum. European Journal of Epidemiology, 15(10), 923-929S.

3. Joe LK, T. N. I., Pohan A. (1960). Subcutaneous Phycomycosis: A new disease found in Indonesia. Archives of Dermatology, 74, 378.

4. Manjir RN, S. V., Balkrishna PN et al. (2009). Subcutaneous phycomycosis in a child. Online Journal of Health and Allied Sciences, 8(3), 14.

5. Sujatha S, S. C., Khyriem AB, Parija SC, THappa DM. (2003). Subcutaneous Zygomycosis caused by Basidiomycosis ranarum. Journal of Medical microbiology, 21(3), 205-206. 


\section{CASE REPORT}

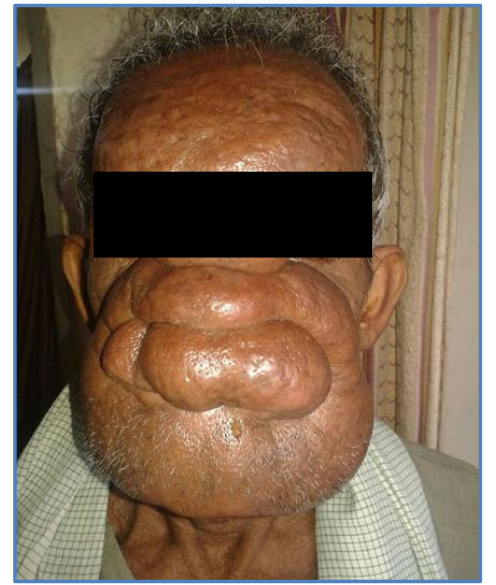

BEFORE TREATMENT

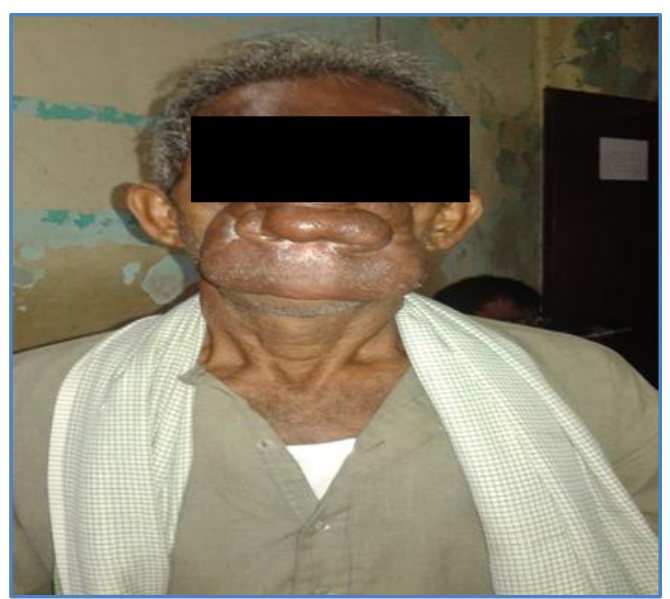

2 MONTHS AFTER TREATMENT

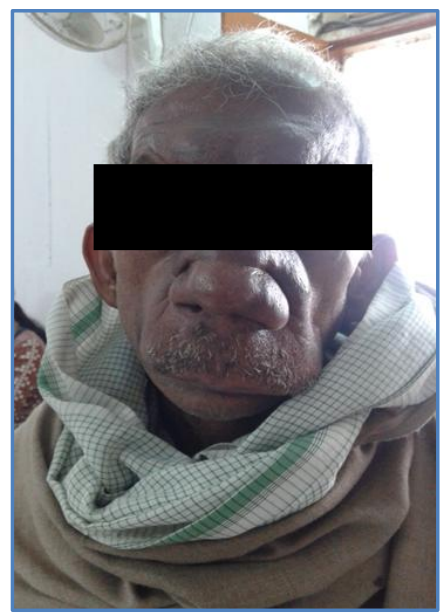

\section{MONTHS AFTER TREATMENT}

\section{AUTHORS:}

1. Garima Sharma

2. Anil Kumar Gupta

\section{PARTICULARS OF CONTRIBUTORS:}

1. $3^{\text {rd }}$ Year Junior Resident, Department of Skin, B. R. D. Medical College, Gorakhpur.

2. Assistant Professor, Department of Skin, B. R. D. Medical College, Gorakhpur.

\section{NAME ADDRESS EMAIL ID OF THE CORRESPONDING AUTHOR: \\ Dr. Garima Sharma, \\ Room No. 52, \\ Indira Girls Hostel, \\ B. R. D. Medical College, \\ Gorakhpur-273013, \\ Uttar Pradesh, India. \\ Email: drsharmaji007@gmail.com}

Date of Submission: 28/11/2014.

Date of Peer Review: 29/11/2014.

Date of Acceptance: 15/12/2014.

Date of Publishing: 22/12/2014. 